\title{
Residential Housing Investment In Spain
}

\author{
Stephan Kienle, Darmstadt University of Technology, Germany
}

\begin{abstract}
Over the last decade, the Spanish housing market has gained a lot of attention due to its dynamics in house prices and residential investments. Our contribution provides a general framework based on the classical user cost approach. We take an equity constraint explicitly into account when modeling a long-term equilibrium. Against the background of theoretical implications we estimate a vector error correction model and find some evidence for the existence of such a financial constraint.
\end{abstract}

Keywords: Housing; Credit Constraint; VECM

\section{INTRODUCTION}

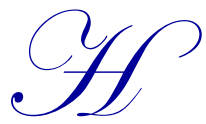

ousing has gained growing recognition in the recent past and has especially been discussed in context with macroeconomics. By affecting aggregate spending, housing is of great importance for a developed economy. As illustrated by Campbell and Cocco (2005) aggregate housing can affect aggregate consumption especially when wealth effects are permanent. Fluctuations in house prices trigger fluctuations in wealth and thus may have both impacts on the real economy as well as on the overall price level. Consequently, interactions between housing markets and other areas of economics have been analyzed. Literature reviews such as Leung (2004) and compilations such as de Bandt et al. (2010) reveal several fields of overlapping research - among them, housing and taxation, monetary policy, business and long cycles.

Against this background, housing is also of importance for a monetary union, where the member countries have abandoned monetary autonomy despite potential divergences in the real sector as discussed for instance by Aspachs-Bracons and Rabanal (2011). For instance, it is crucial to get a better understanding of the determinants of housing in the member countries to judge the effects of common monetary policy stances as transmission might vary across countries due to institutional differences. The existence of credit constraints could impact housing investment decisions and might hamper transmission in some countries much stronger than in other countries.

This paper takes a different perspective on how to identify credit constraints households are faced with. Therefore, we apply a concept of user cost which is lifting the perfect capital market assumptions and restricts loans to collateral. Theoretical considerations suggest that the existence of a credit constraint would imply a user cost representation that depends inter alia on an equity ratio. In our empirical analysis we focus on the Spanish housing market as it has received particular attention over the last decade. Similar to the US housing market, boom and bust in Spain was of great scale and length. In contrast to related contributions such as in Antipa and Lecat (2010), who find that the user cost has no significant impact on demand prices, we reveal a significant and as expected negative influence on housing investment. Furthermore, we find empirical evidence in favor of a financial constraint which is part of a long-run equilibrium as suggested by theory.

The remainder of the paper is organized as follows: Section 2 provides a theoretical framework which includes an equity constraint for residential investments. In Section 3, we present estimation results for Spain based on a vector error correction model. We find some evidence for the existence of an equity constraint which is relevant in the equilibrium relation.

\section{THEORETICAL FOUNDATIONS}

Duemmler and Kienle (2010) extended the neoclassical approach of Dougherty and Van Order (1982) and derived a theoretical framework containing a financial constraint which is relevant for the representative household's 
decision on non-durable consumption and residential investment. In the paper at hand the approach is further evolved to model the capital requirements for homeowners in Spain. We therefore introduce an equity constraint binding for the household. In nominal terms the budget constraint of a representative household is given by:

$Y_{t}+A_{t}-S_{t}=C_{t}+X_{t}-Z_{t}$

Nominal income (Y) as well as internal and external liquid funds obtained through debt expansion (-S) or accrued savings (A) are spent for consumption (C), gross housing investment (X) as well as interest payments (Z) on household's debts. There are two restrictions with respect to the budget constraint. First, to finance the nominal stock of housing $\mathrm{H}$, the representative household can either use internal funds, i.e. accumulated savings of each period before, E, or can take a mortgage loan $\mathrm{M}$ at the nominal interest rate $\mathrm{i}_{\mathrm{h}}=\mathrm{r}+\pi_{\mathrm{h}}$. A mortgage loan requires that housing stock can be provided as collateral:

$$
\begin{aligned}
& S_{t}=M_{t+1}-M_{t} \\
& A_{t}=\sum_{j=t}^{t-k} E_{j}
\end{aligned}
$$

where $\mathrm{k}$ is the first period of saving. The interest payment for a mortgage can be expressed as follows:

$\mathrm{Z}_{\mathrm{t}}=\mathrm{i}_{\mathrm{h}, \mathrm{t}} \mathrm{M}_{\mathrm{t}}$

Please note that for the sake of simplification saving is tied to the funding of housing only and not available for other purposes as intertemporal consumption smoothing. This feature of the model, however, has no major impacts on its key results.

Second, savings go along with opportunity costs since this kind of liquid funds are free of earnings. Assuming that the opportunity costs arising from saving are higher than the rate for a mortgage the household intends a parsimonious allocation of own funds. Given this preference structure, the household always take the maximum amount of mortgage credit to finance housing. Capital requirements can be defined as a share $\eta$ of the nominal housing stock to be provided as equity.

The real stock of housing evolves according to:

$\mathrm{h}_{\mathrm{t}+1}=(1-\delta) \mathrm{h}_{\mathrm{t}}+\mathrm{x}_{\mathrm{t}}$

where $\mathrm{x}=\mathrm{X} / \mathrm{p}$ is the real gross housing investment; $\mathrm{p}_{\mathrm{h}}$ is the house price index and $\mathrm{p}$ the consumer price index with associated inflation rates $\pi_{\mathrm{h}}$ and $\pi$ respectively. $\delta$ is the economic depreciation rate of the housing stock, which comprises both technical decay as well as capital gains or losses.

Suppose that the preferences of the representative household are reflected by the instantaneous utility function $\mathrm{u}(\mathrm{c}, \mathrm{h})$ with $\mathrm{u}^{\prime}>0, \mathrm{u}^{\prime \prime}<0$ where $\mathrm{c}$ is the consumption of a non-durable good and $\mathrm{h}$ is the use of housing services.

Let us assume that the household maximizes life-time utility represented by a time-separable function:

$\mathrm{V}=\sum_{\mathrm{t}=0}^{\mathrm{T}} \rho_{\mathrm{t}}^{\mathrm{t}} \mathrm{u}\left(\mathrm{c}_{\mathrm{t}}, \mathrm{h}_{\mathrm{t}}\right)$

where $\rho$ is a positive discount factor. Including the real budget constraint, i.e. the budget constraint in units of consumer prices, the dynamic Lagrange function is given by: 
$L=\sum_{t=0}^{T} \rho_{t}^{t}\left(u\left(c_{t}, h_{t}\right)+\lambda\left(y_{t}-c_{t}-q_{t}\left(x_{t}+i(1-\eta) h_{t}+\eta h_{t}+s_{t}\right)\right)\right)$

and yields the following first order conditions:

$\frac{\partial \mathrm{L}}{\partial \mathrm{c}_{\mathrm{t}}}=\rho_{\mathrm{t}}^{\mathrm{t}} \frac{\partial \mathrm{u}}{\partial \mathrm{c}_{\mathrm{t}}}-\lambda \rho_{\mathrm{t}}^{\mathrm{t}} \stackrel{!}{=} 0$

$\frac{\partial \mathrm{L}}{\partial \mathrm{h}_{\mathrm{t}+1}}=\rho_{\mathrm{t}}^{\mathrm{t}+1} \frac{\partial \mathrm{u}}{\partial \mathrm{h}_{\mathrm{t}}}-\lambda \rho_{\mathrm{t}}^{\mathrm{t}+1} \mathrm{q}_{\mathrm{t}}\left(\delta+\mathrm{i}_{\mathrm{h}, \mathrm{t}}(1-\eta)\right)+\lambda \rho_{\mathrm{t}}^{\mathrm{t}} \mathrm{q}_{\mathrm{t}}\left(\pi_{\mathrm{h}, \mathrm{t}}-\eta\left(1+\pi_{\mathrm{h}, \mathrm{t}}\right)\right) \stackrel{!}{=} 0$

which can be written more compactly:

$\mathrm{u}_{\mathrm{c}}=\lambda$

$\mathrm{u}_{\mathrm{h}}=\lambda \mathrm{q}_{\mathrm{t}}\left(\delta_{\mathrm{t}}+\mathrm{i}_{\mathrm{h}, \mathrm{t}}(1-\eta)-\frac{\pi_{\mathrm{h}, \mathrm{t}}-\eta\left(1+\pi_{\mathrm{h}, \mathrm{t}}\right)}{\rho_{\mathrm{t}}}\right)$

Optimization implies that consumption of the non-durable goods must be extended up to the point where the marginal rate of utility of consuming goods is equal to the marginal costs of financing consumption. By analogy, consumption of housing services must be extended until the marginal utility of housing services matches the marginal costs of buying an extra unit of housing stock which is the discounted sum of the current and the following periods:

$$
\frac{\mathrm{u}_{\mathrm{h}}}{\mathrm{u}_{\mathrm{c}}}=\mathrm{q}_{\mathrm{t}}\left(\delta_{\mathrm{t}}+\mathrm{i}_{\mathrm{h}, \mathrm{t}}(1-\eta)-\frac{\pi_{\mathrm{h}, \mathrm{t}}-\eta\left(1+\pi_{\mathrm{h}, \mathrm{t}}\right)}{\rho_{\mathrm{t}}}\right)
$$

which can be reformulated as:

$$
\frac{\mathrm{u}_{\mathrm{h}}}{\mathrm{u}_{\mathrm{c}}}=\mathrm{UC}+\eta \mathrm{FC}
$$

with the basic user cost representation as illustrated for instance in Jorgenson (1963):

$$
\mathrm{UC}=\mathrm{q}_{\mathrm{t}}\left(\delta_{\mathrm{t}}+\mathrm{i}_{\mathrm{h}, \mathrm{t}}(1-\eta)-\frac{\pi_{\mathrm{h}, \mathrm{t}}}{\rho_{\mathrm{t}}}\right)
$$

and the financial constraint:

$$
\mathrm{FC}=\frac{\mathrm{q}_{\mathrm{t}}\left(1+\pi_{\mathrm{h}, \mathrm{t}}-\mathrm{i}_{\mathrm{h}, \mathrm{t}} \rho_{\mathrm{t}}\right)}{\rho_{\mathrm{t}}}
$$

If there is no equity constraint the user cost representation will collapse to the classical one UC. Otherwise, the financial constraint will be relevant depending inter alia on the equity ratio $\eta$. The partial effect of $\eta$ is according to intuition, i.e. an increase in the equity constraint would hamper housing investment. 


\section{EMPIRICAL EVIDENCE}

\subsection{Data Description}

To test the relevance of a credit constraint on the Spanish housing market, we confront our theoretical derivations with reality. To explain housing, we consider our extended user cost definition and include variables that may be important for the decision and ability of a household to invest in housing. Hence, we consider disposable income and net financial assets as crucial in what follows.

Housing investment $\mathrm{HI}$ is derived from the data presented by the Fundacion BBVA. Net financial assets NFA are taken from Eurostat. Disposable income DI stems from the Institudo Nacional de Estadistica. The development of the housing prices is based on the house price index provided by the Ministerio de la Vivienda de Espana and the consumer price index for housing available from the Institudo Nacional de Estadistica. For the calculation of the user cost expression and the extension term we use ten year government bond yields which are published by the Banco de Espana and Eurostat, respectively. The sample covers quarterly data from the first quarter 1981 to the first quarter 2012.

We perform unit root tests to obtain some insights on the trending behavior of the series included in the empirical analysis. For the sake of unit root tests we disentangle the user cost representation into two terms UC and FC. Augmented Dickey-Fuller (ADF) and Phillips-Perron (PP) test for a unit root in the series. The test proposed by Kwiatkowski et al (1992) (KPSS) assumes stationarity under the null. The results suggest that all series contain a unit root.

Table 1: Unit Root Tests

\begin{tabular}{|l|c|c|c|c|}
\hline & Deterministic Terms & ADF & PP & KPSS \\
\hline HI & $\mathrm{c}, \mathrm{t}$ & $-2.20(3)$ & $-2.80(8)$ & $0.19(9)^{* *}$ \\
\hline DI & $\mathrm{c}, \mathrm{t}$ & $-2.83(0)$ & $-2.81(3)$ & $0.29(9)^{* * *}$ \\
\hline NFA & $\mathrm{c}, \mathrm{t}$ & $-1.19(0)$ & $-1.41(2)$ & $0.27(9)^{* *}$ \\
\hline UC & $\mathrm{c}$ & $-1.87(1)$ & $-1.58(3)$ & $0.35(9)^{*}$ \\
\hline FC & $\mathrm{c}$ & $-1.84(2)$ & $-1.57(8)$ & $0.90(9)^{* * *}$ \\
\hline
\end{tabular}

$*(* *, *)$ mean that the null can be rejected at a $1 \%(5 \%, 10 \%)$ level. Determinstic terms are a constant c and a trend t. The numbers in brackets represent the lag length in the ADF test and the bandwidth parameter in the PP and KPSS procedures. The lag length was selected by minimizing the Schwarz (1978) criterion (SC) with a maximum lag length of 13 . The bandwidth parameter was chosen by the procedure suggested by Newey and West (1994). Critical values for the ADF and the PP tests are taken from MacKinnon (1996) and for KPSS from Kwiatkowski et al (1992).

\subsection{Vector Error Correction Model}

Since the time series are supposed to be nonstationary, we employ the concept of cointegration which allows modeling accurately the interactions between the variables of interest. After determining the lag length and the cointegration rank, we use a vector error correction model (VECM) to reveal the long-run relationships.

For specifying the VECM, the lag order $\mu$ and the cointegration rank $r$ have to be determined first. We choose the lag order by fitting unrestricted VAR $(\mu)$ models in levels for the set of lag orders $\mu=0$ to 8 . The estimator selected is of the order $\mu$, which minimizes standard information criteria AIC, SC and HQ, following Akaike (1969, 1971) (AIC), Schwarz (1978) (SC), and Hannan and Quinn (1979) (HQ). The results are presented in Table 2. Optimum lag order is indicated by an asterisk and ranges from $\mu=1$ (SC, HQ) to $\mu=3$ (AIC).

Table 2: VAR Lag Order Selection

\begin{tabular}{|l|c|c|c|}
\hline Lag & AIC & SC & HQ \\
\hline $\mathbf{0}$ & -6.84 & -6.72 & -6.79 \\
\hline $\mathbf{1}$ & -24.01 & $-23.32^{*}$ & $-23.73^{*}$ \\
\hline $\mathbf{2}$ & -24.10 & -22.82 & -23.58 \\
\hline $\mathbf{3}$ & $-24.31^{*}$ & -22.45 & -23.56 \\
\hline $\mathbf{4}$ & -24.18 & -21.84 & -23.29 \\
\hline $\mathbf{5}$ & -24.30 & -21.29 & -23.08 \\
\hline $\mathbf{6}$ & -24.26 & -20.66 & -22.80 \\
\hline $\mathbf{7}$ & -24.17 & -19.99 & -22.47 \\
\hline $\mathbf{8}$ & -24.10 & -19.34 & -22.17 \\
\hline
\end{tabular}


Additionally, we perform residual autocorrelation tests in the $\operatorname{VAR}(\mu), \mu=1$ to 5 . The hypotheses of no serial correlation of order $\lambda=1$ to 6 for the VAR models with $\mu=1$ to 3 are mostly rejected at the 0.05 level. Due to the autocorrelation properties of residuals, we therefore use as lag orders $\mu=4$. Conditional on $\mu=4$, we test for the cointegration rank using the procedure proposed by Johansen (1995). The results suggest that there is exactly one cointegrating relation between the I(1) variables as shown in Table 3.

Table 3: Test for Cointegration Rank (Trace and Maximum Eigenvalue)

\begin{tabular}{|l|c|c|c|c|}
\hline \multicolumn{1}{|c|}{ Rank r } & Trace Statistic & $\mathbf{0 . 0 5}$ Critical Value & Max. Eigenvalue Statistic & 0.05 Critical Value \\
\hline $\mathbf{r}=\mathbf{0}$ & 77.44 & 69.82 & 34.23 & 33.88 \\
\hline $\mathbf{r} \leq \mathbf{1}$ & 43.21 & 47.86 & 23.62 & 27.58 \\
\hline $\mathbf{r} \leq \mathbf{2}$ & 19.59 & 29.80 & 12.05 & 21.13 \\
\hline $\mathbf{r} \leq \mathbf{3}$ & 7.55 & 15.49 & 4.82 & 14.26 \\
\hline
\end{tabular}

** denotes rejection of the null at the $5 \%$ level; linear deterministic trend assumed in data; critical values are drawn from MacKinnon et al (1999).

We impose the restriction, that the extended user cost expression is weakly exogenous. This is confirmed by a LR test for binding restrictions on the corresponding adjustment parameters. According to the test results, the hypothesis of weakly exogenity of UC and FC cannot be rejected with a probability of 0.07 which corresponds to a $\chi^{2}(2)$ statistic of 5.22 .

The resulting reduced rank regression of the $\operatorname{VECM}(4)$ yields the cointegrating relation:

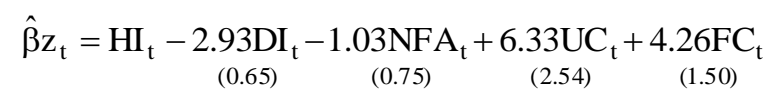

where standard errors are given in parentheses. We find a rather high value for long-run income elasticity of above 1. This might yet be reasonable as housing can be categorized as a superior good. A similar interpretation and similar elasticities of income can be found in Antipa and Lecat (2010) or Martinez-Pages and Maza (2003) among others.

The vectors of adjustment parameters are given by:

$$
\hat{\alpha}=\left[\begin{array}{c}
-0.05 \\
(0.02) \\
0.02 \\
(0.01) \\
0.00 \\
0.00) \\
0.00 \\
0.00
\end{array}\right]
$$

By rearranging terms in the cointegration relation we can solve for an estimate for the equity ratio $\eta$. We therefore slightly adopt the representation given above in equation (16):

$\hat{\beta} \mathrm{z}_{\mathrm{t}}=\mathrm{HI}_{\mathrm{t}}-2.93 \mathrm{DI}_{\mathrm{t}}-1.03 \mathrm{NFA}_{\mathrm{t}}+6.33\left(\mathrm{UC}_{\mathrm{t}}+0.67 \mathrm{FC}_{\mathrm{t}}\right)$

Thus it follows that in the long run an average equity ratio of approximately $67 \%$ can be derived from the estimation. This is relatively high, but still within a plausible range. The result is also in line with the findings in IMF (2008) which states that in continental Europe some countries such as Spain only provide limited access to mortgage credit for households. This feature is reflected by lower loan-to-value ratios and shorter mortgage terms. 


\section{CONCLUDING REMARKS}

The paper contributes to shed some light on the Spanish housing market, which has gained a lot of attention in recent years. Insight from the housing market may be of relevance for various policy areas. Understanding the determinants of housing investment could for instance be relevant for taxation or monetary policy.

We enrich the findings of other studies by taking a financial constraint explicitly into account when modeling the long-term relation between housing investment, disposable income, net financial assets as well as the user cost of housing and an equity constraint. The equity constraint is introduced to restrict the overall housing stock that a household can finance. After a theoretical illustration we present empirical evidence for the existence of an equity constraint in a VECM. The estimated value for the constraint based on the long run relation of the aforementioned variables is plausible. In contrast to other studies, the user costs of housing as well as the financial constraint both have a significant impact on housing investment in the long-run. This is similar to the findings for Germany, where Duemmler and Kienle (2010) suggest the existence of financial market imperfections on the German housing sector.

Further studies for different countries of the European Monetary Union would be useful to develop a better understanding of this topic and to assess whether and to what extent households are faced with a credit constraint. From a central bank's perspective this might be relevant as structural differences could lead to different reactions on monetary policy stances as shown by the IMF (2008), i.e. different market imperfections could impact transmission and enlarge heterogeneity within a monetary union.

\section{NOTE}

The views expressed in this paper are those of the author alone. Any remaining shortcomings are entirely the responsibility of the author.

\section{AUTHOR INFORMATION}

Stephan Kienle is a doctoral student at the Darmstadt University of Technology. He did his undergraduate studies in business sciences and economics at the University of Applied Sciences of the Deutsche Bundesbank and at the Goethe University at Frankfurt, where he finally graduated with a Master equivalent degree in economics. His main research interest is in macroeconomics with a special focus on monetary policy. E-mail: stephan.kienle@stud.tudarmstadt.de

\section{REFERENCES}

1. Akaike, H. (1969), Autoregressive model fitting for control, Annals of the Institute of Statistical Mathematics 21(1), 243-247.

2. Akaike, H. (1971), Fitting autoregressive models for prediction, Annals of the Institute of Statistical Mathematics 23(1), 163-180.

3. Antipa, P. and R. Lecat (2010), A structural Model of Housing Market, in: O. de Bandt, T. Knetsch, J. Penalosa, F. Zollino (eds.): Housing Markets in Europe, Springer, 161-186.

4. Aspachs-Bracon, O. and P. Rabanal (2011), The Effects of Housing Prices and Monetary Policy in a Currency Union, International Journal of Central Banking 7(1), 225-274.

5. Campbell, J. Y. and J. F. Cocco (2005), How do House Prices affect Consumption? Evidence from Microdata, NBER Working Paper 11534.

6. De Bandt, O., T. Knetsch, J. Penalosa, F. Zollino (eds.): Housing Markets in Europe, Springer.

7. Dougherty, A. and R. Van Order (1982), Inflation, Housing Costs, and the Consumer Price Index, The American Economic Review 72(1), 154-164.

8. Duemmler, T. and S. Kienle (2010), User Costs of Housing - When Households face a Credit Constraint: Evidence for Germany, in: O. de Bandt, T. Knetsch, J. Penalosa, F. Zollino (eds.): Housing Markets in Europe, Springer, 213-239. 
9. Hannan, E. J. and B. G. Quinn (1979), The Determination of the Order of an Autoregression, Journal of the Royal Statistical Society 41(2), 190-195.

10. IMF (2008), The Changing housing cycle and the implications for monetary policy, World Economic Outlook 04/2008, 103-132.

11. Johansen, S. (1995), Likelihood-based Inference in Cointegrated Vector Autoregressive Models, Oxford, 1995.

12. Jorgenson, D. W. (1963), Capital Theory and Investment Behaviour, The American Economic Review 53(2), 247-259.

13. Kwiatkowski, D. A., P. Phillips, P. Schmidt and Y. Shin (1992), Testing the Null Hypothesis of Stationarity against the Alternative of a Unit Root, Journal of Econometrics 54(1), 159-178.

14. Leung, C. (2004), Macroeconomics and housing: a review of the literature, Journal of Housing Economics 13(4), 249-267.

15. MacKinnon, J. G. (1996), Numerical distribution functions for unit root and cointegration tests, Journal of Applied Econometrics 11(6), 601-618.

16. MacKinnon, J. G., A. A. Haug and L. Michelis (1999), Numerical Distribution Functions of Likelihood Ratio Tests for Cointegration, Journal of Applied Econometrics 14(5), 563-577.

17. Martinez-Pages, J. and L. A. Maza (2003), Analysis of house prices in Spain, Banco de Espana Working Paper Series No. 0307.

18. Newey, W. K. and K. D. West (1994), Automatic Lag Selection in Covariance Matrix Estimation, Review of Economic Studies 61(4), 631-653.

19. Schwarz, G. (1978), Estimating the dimension of a model, The Annals of Statistics 6(2), 461-464. 
NOTES 